\title{
Zero displacement cost model: a simplified RM model for post-COVID-19 O\&D management
}

\author{
Landie Qiu ${ }^{1}$
}

Received: 6 March 2020 / Accepted: 11 August 2020 / Published online: 20 September 2020

(c) Springer Nature Limited 2020

\begin{abstract}
In the airline industry, the aim of O\&D RM is to optimize network revenue by increasing seat availability for high-revenue connecting passengers while preventing connecting passengers from displacing high-yield local passengers to reduce displacement costs. Traditional O\&D models rely heavily on complex historical data analysis. The outbreak of COVID-19 has led to an unprecedented disruption of the global airline industry. It has reset historical data, thereby reducing the reliability of the traditional forecasting and optimization results. This paper proposes Zero Displacement Cost (0DC) model as a simplified and flexible model for airlines to manage O\&D in the post-COVID-19 world.
\end{abstract}

Keywords Revenue management $\cdot$ O\&D $\cdot$ Displacement cost $\cdot$ COVID-19 $\cdot$ Forecasting $\cdot$ Network optimization

\section{Introduction}

The development of Revenue Management (RM) in the airline industry started with overbooking in the 1960s and simple two-fare offerings in the 1970s. US airline deregulation in the 1970s and the resulting plethora of airfares in the 1980s led to further refinements in RM practices. These refinements included introducing multiple forecasting and optimization methods. By the 1990s, a few airlines had mastered leg-based RM.

While many passengers' itineraries involve one single flight leg (point-to-point), a significant portion of passengers' true Origin and Destination (O\&D) involve more than one flight leg. This can be particularly relevant for airlines that arrange their flight schedules using the hub-and-spoke concept and offer many connecting O\&Ds. From 1990s, airlines have realized that they should aim to optimize revenue over the whole network, rather than on individual legs (Bertsimas et al. 2005), so O\&D RM was born. It has further accelerated the development of hub-and-spoke networks with more connecting flights and international routes operated.
However, the outbreak of COVID-19 (Coronavirus Disease 2019) has brought the airline industry to a standstill in 2020. Governments have issued travel bans, demands have plummeted, and airlines have massively reduced capacity, especially for international routes. Traditional O\&D RM models rely on stable historical data to generate robust demand forecasting, but COVID-19 outbreak has reset historical data by making them irrelevant or unusable, RM managers have to set fares from scratch for the postCOVID-19 recovery. Additionally, because of the complicity of traditional models, it's difficult to calibrate them to respond to market uncertainties, let alone the extreme circumstances of COVID-19. The aim of this paper is to propose a simplified and flexible O\&D RM model to quickly cope with COVID-19 disruption.

The remainder of this paper is structured as follows: the second section first reviews the traditional O\&D optimization models and their limitations. The next section proposes a new O\&D RM model and it is illustrated by asking and answering three questions. To evaluate this model, a simulation study has been carried out and the result analysis is discussed. The last section summarizes this paper.

Landie Qiu

landie.qiu@accelya.com

1 Singapore, Singapore 


\section{Review of O\&D RM models}

This section gives an overview of traditional O\&D RM models. There are three main methodologies: linear programming (LP), nesting and booking limits, and bid price (BP). The classic models under each methodology are addressed and their limitations are categorized in the end of this section.

\section{Linear programming based models}

Linear programming (LP) is a constrained optimization technique (Williamson 1992) with two components: the objective function and a set of constraints, as following.

Goal: maximize

Revenue $=\sum_{\mathrm{ODF}} f_{\mathrm{ODF}} \cdot x_{\mathrm{ODF}}$

Subject to:

$\sum_{\mathrm{ODF}} x_{O D F} \leq C_{j}, \quad$ for all legs $j$,

$x_{\mathrm{ODF},} \leq D_{j}$, for all ODF' $s$,

$x_{\mathrm{ODF}} \geq 0$, integer, for all $O D F^{\prime} s$.

In the objective function, the goal is to maximize the total revenue in the network. ODF represents origin, destination and fare class. $f_{\mathrm{ODF}}$ is the fare offered to one particular ODF. $x_{\mathrm{ODF}}$ is the optimal number of seats sold to an ODF. For the restriction set, the first restriction is a capacity restriction-for each leg $j$, the number of seats sold must be less than or equal to the capacity. The second restriction is a demand restriction-for each ODF, the number of seats sold must be less than or equal to the mean forecasted demand. The last restriction is a nonnegative constraint.

There are three limitations in linear programming (Wei 1997). First, it requires a huge amount of data collection and calculation on ODF level, so it is a very time-consuming and easy-to-go-wrong process. Second, the forecast demand constraints are hard to set. Finally, "small numbers" problem-because the whole network involves numerous ODF, each ODF may just end with a very small number of samples.

\section{Nesting and booking limits based models}

Nesting is a method to organize and manage inventory. There are three main nesting methods: discrete, serial nesting (full nesting) and parallel nesting. The nesting method addressed in this paper is serial nesting. In a serial nesting environment, there are hierarchical booking limits-the available seats in one nested class are also available to book in any higher nested classes, but not in a reverse way (McGill and Van 1999).

EMSRb (Expected Marginal Seat Revenue) model is a booking limits model used for leg-based revenue optimization model, developed by Belobaba. Based on EMSRb model, two models are developed for network O\&D RM optimization: virtual nesting method (VEMSRb) and displacement adjusted virtual nesting (DAVN).

\section{Virtual nesting method (VEMSRb)}

Boeing proposed Virtual Nesting method (VEMSRb) to take total O\&D fares into consideration. It prioritizes a wide variety of O\&D fares using a larger number of virtual classes and ranks the priority to seats by total fares (Table 1).

As a network optimization model, VEMSRb is too "greedy" for long-haul O\&D passengers, because it doesn't consider the costs of O\&D passengers for displacing the upline or down-line local passengers. In the underlined examples, B class in A-B-C itinerary (\$500) is categorized in virtual class 2 with higher priority, but, two local itineraries of $\mathrm{Y}$ class in A-B (\$380) and B class in B-C (\$420) are categorized in lower virtual classes 5 and 4 , with a higher total revenue (\$800). Therefore, applying VEMSRb model can take one connecting passenger and displaces two or more local passengers whose total fares could be higher. The lost revenue from the displacement is named as a displacement cost.

\section{Displacement adjusted virtual nesting (DAVN)}

Williamson (1992) proposed a new virtual nesting model by taking the displacement costs into consideration as Displacement Adjusted Virtual Nesting Model (DAVN). This model creates "pseudo fares" to map virtual nesting, which are revenue contributions after considering displacement impact. The pseudo fares for connecting passengers equal to their total fares minus the displacement costs:

Fare $_{\mathrm{Leg} 1}=\mathrm{ODF}-\sum_{l \in L, l \neq \mathrm{Leg} 1}$ Displacement $_{l}$

In this formula, displacement ${ }_{1}$ represents the displacement cost on other legs of this itinerary beside leg 1 . It can be estimated by shadow price values generated from linear programming. In an airline RM environment, the shadow price reflects the estimated seat value change due to releasing one unit of marginal variation in one constraint. DAVN model uses shadow prices as references for displacement costs, so it requires processing linear programming frequently to update 
Table 1 An example of virtual nesting method

\begin{tabular}{|c|c|c|c|c|c|c|c|}
\hline \multicolumn{2}{|c|}{ A-B itinerary fares } & \multicolumn{2}{|c|}{ A-B-C itinerary fares } & \multicolumn{2}{|c|}{ A-B-D itinerary fares } & \multicolumn{2}{|c|}{ B-C itinerary fares } \\
\hline Class & Fare $\$$ & Class & Fare $\$$ & Class & Fare $\$$ & Class & Fare $\$$ \\
\hline$\underline{Y}$ & 380 & $\mathrm{Y}$ & 620 & $\mathrm{Y}$ & 550 & $\mathrm{Y}$ & 500 \\
\hline $\mathrm{B}$ & 350 & $\underline{B}$ & 500 & $\mathrm{~B}$ & 480 & $\underline{B}$ & 420 \\
\hline M & 300 & M & 400 & M & 420 & M & 350 \\
\hline Q & 200 & Q & 290 & Q & 340 & Q & 300 \\
\hline \multicolumn{8}{|c|}{ O\&D network virtual class } \\
\hline Virtual class & Fare range $\$$ & \multicolumn{6}{|c|}{ O\&D class and itinerary } \\
\hline 1 & $600+$ & $\mathrm{Y}$ & $\mathrm{A}-\mathrm{B}-\mathrm{C}$ & & & & \\
\hline 2 & $500-599$ & $\mathrm{Y}$ & A-B-D & $\underline{\mathrm{B}}$ & $\underline{\mathrm{A}}-\underline{\mathrm{B}}-\underline{\mathrm{C}}$ & $\mathrm{Y}$ & $\mathrm{B}-\mathrm{C}$ \\
\hline 3 & $450-499$ & $\mathrm{~B}$ & A-B-D & & & & \\
\hline 4 & $400-449$ & M & A-B-D & M & $\mathrm{A}-\mathrm{B}-\mathrm{C}$ & $\underline{\mathrm{B}}$ & $\underline{B}-\underline{C}$ \\
\hline 5 & $350-399$ & $\underline{Y}$ & $\underline{\mathrm{A}}-\underline{\mathrm{B}}$ & B & $\mathrm{A}-\mathrm{B}$ & M & $\mathrm{B}-\mathrm{C}$ \\
\hline 6 & $300-349$ & Q & A-B-D & M & $\mathrm{A}-\mathrm{B}$ & Q & $\mathrm{B}-\mathrm{C}$ \\
\hline 7 & $250-299$ & Q & $\mathrm{A}-\mathrm{B}-\mathrm{C}$ & Q & A-B & & \\
\hline
\end{tabular}

shadow price values, thereby adopting the limitations from linear programming.

\section{Bid price based models}

One commonly used O\&D RM methodology is bid price control, which is defined as a method used to make decisions of accepting or rejecting booking requests based on minimum acceptable fare values (Belobaba et al. 2015). Two methods are used to calculate bid price: heuristic bid price and deterministic bid price.

\section{Heuristic bid price}

Heuristic bid price model assumes the bid prices for local passengers are their EMSR values. Bid prices for connecting passengers are the combinations of EMSR values on all legs, as following.

$\mathrm{BP}_{1}=\mathrm{EMSR}_{1}+d * \mathrm{EMSR}_{2}$

$\mathrm{BP}_{2}=\mathrm{EMSR}_{2}+d * \mathrm{EMSR}_{1}$

$\mathrm{BP}_{c}=\mathrm{BP}_{1}+\mathrm{BP}_{2}$

where in this formula, $\mathrm{BP}_{1}$ and $\mathrm{BP}_{2}$ are the bid prices on leg 1 and leg 2 for the connecting passenger, respectively. $\mathrm{BP}_{\mathrm{C}}$ is the total bid price for the connecting passenger. " $d$ " is the product of probabilities of the local passengers on both legs. If the requested fare of a connecting passenger is larger than $\mathrm{BP}_{\mathrm{C}}$, the airline will accept it; otherwise, reject it. The limitations of EMSR values are addressed in the following section of model limitation summary.

\section{Deterministic bid price}

The difference between deterministic bid price and heuristic bid price is how displacement cost is calculated. Heuristic bid price uses EMSR values to estimate displacement cost; deterministic bid price uses shadow prices to estimate the displacement cost, which are generated from linear programming.

\section{Summary of model limitations}

Although many traditional O\&D RM models are theoretically optimal, they are facing some practical challenges and limitations, which are categorized as following.

\section{High complexity}

Most O\&D models require an ODF level of data collection and forecasting entities. Such detailed level of granularity increases the number of forecasting entities exponentially (Tirumalachetty et al. 2017). Every model is based on some assumptions and every forecasting result has a forecast error. From a network perspective, as the model complexity increases, the noises and errors also increase. The sum of the assumptions, noises and errors reduces forecast accuracy and jeopardizes optimization reliability. This has been further amplificated during COVID-19 time due to unstable historical data. 


\section{Small numbers problem}

The granularity of ODF data collection results small numbers of historical data sample. For example, a connecting flightpath may have historical data sample as $(0,1,0,0,2,1$, 0 ) in one week, with a small mean as 0.57 and a high standard deviation as 0.73 . Such data characteristics are problematic for traditional forecasting and optimization models. Moreover, the "small numbers" problem have become "zero numbers" problem during COVID-19 outbreak, because many bookings in ODF level have dropped to 0 .

\section{Price elasticity}

VEMSRb, DAVN and heuristic bid price models are based on EMSRb models, which was developed under an important assumption that demand for every fare class is independent and separate, so it assumes no elasticity for passengers who buy different fare classes. However, in realistic scenarios, high-yield passengers may buy low fare tickets if available, and low-yield passengers may buy high fare tickets if low fare tickets are not available. Most customers have some levels of price elasticity, so the mixed buying intentions challenge the assumptions of EMSRb related models. In addition, the "spiral-down" effect of EMSRb model has lead less protection in high classes with an undesired negative impact on network revenue.

\section{Tradeoff between local passengers vs. connecting passengers}

Local passengers and connecting passengers share seats availability on flights. One long-haul connecting passenger provide more itinerary revenue than one local passenger, but the connecting passenger could displace two or more local passengers, whose total revenue could be higher than the connecting passenger. Determine the displacement cost and the tradeoff between local versus connecting passengers has always been a challenge for O\&D optimizations.

\section{Slow response}

For every coming O\&D booking request, airlines prefer instant or real-time price quote from RM systems. This requires quick response and frequent model recalculation, but the complexity of traditional models limits the programming frequency and performance. Secondly, most traditional O\&D models are slow to adapt to changing markets, let alone the volatile markets caused by a pandemic or other unexpected crisis.

\section{Zero Displacement Cost Model}

Considering the above model limitations, a new O\&D model-zero displacement cost (ODC) model is proposed. As discussed, one very important decision in O\&D RM is the tradeoff between local passengers versus connecting passengers. Airlines wish to increase seats availability to highrevenue connecting passengers, while prevent connecting passengers from displacing high-yield local passengers. To determine this tradeoff, three questions are raised:

\section{Will a connecting passenger displace a local passenger or not?}

It depends on the demand of local passengers.

\section{Spoilage}

A spoilage situation is when the demand is low and there are empty seats left at the departure day (day 0). In this scenario, empty seats remain empty even if no connecting passengers are taken, so taking one connecting passenger does not displace any local passengers.

\section{Spill}

A spill situation is when the demand is high and there are no empty seats left at the departure day (day 0 ). In this scenario, taking one connecting passenger does displace local passengers and a displacement cost incurs.

Most traditional O\&D models calculate displacement costs for all connecting passengers. ODC model considers spoilage situations as the situations when no displacement costs incur. The next step is to forecast spoilage/spill situations.

\section{How to forecast the spoilage/spill situations?}

The transition point for spoilage/spill situations is when the booking number equals to the lid number at the departure day, with an exact $100 \%$ load factor (LF). Lid number is defined as the number of the maximum available seats for sale on one flight. It is also named as cabin authority number in some RM systems. To clarify, if there is no overbooking or restricted booking, the lid number equals to the capacity number. If there is overbooking, the lid number equals to capacity number plus overbooking number. If there is restricted booking, the lid number equals to capacity number minus restricted booking number.

ODC model applies booking curve methodology to forecast the spoilage/spill. A flight booking curve reflects the 
booking pace by showing the number of bookings on each NDO (number of day out) on a flight level. It is represented graphically, NDO on the $X$-axis and LF on the $Y$-axis. It has been commonly used in airline industry to keep track of bookings and analyze booking patterns. Compared with traditional models, the needed data for generating booking curves have lower granularity, as they are in flight level, not ODF level. Even during COVID-19 time, analysts can utilize limited data and structured test-and-learn approach to build the booking curves (Fig. 1).

This example booking curve is made by historical booking data from local passengers. The LF on NDO 0 is $71 \%$, indicating the booking number is less than the lid number on the departure day, so this flight is in a spoilage situation. Based on the growth pattern of the historical booking curve, another booking curve with $100 \%$ LF on NDO 0 can be generated, which is defined as the "full booking curve" in ODC model. The NDO LF on the full booking curve is calculated as following:

$\mathrm{FL}_{0}=100 \%$

$\mathrm{FL}_{n}=\frac{\mathrm{FL}_{n-1} * \mathrm{HL}_{n}}{\mathrm{HL}_{n-1}}, \quad(n \geq 1)$

where in this formula, $\mathrm{n}$ indicates NDO, FL is the load factor for full booking curve and HL is the load factor for historical booking curve. $\mathrm{FL}_{0}=100 \%$ refers the $\mathrm{LF}$ for the full booking curve on NDO 0 is always equal to $100 \%$. In the example where $\mathrm{HL}_{0}$ and $\mathrm{HL}_{1}$ are $71 \%$ and $70 \%, \mathrm{FL}_{1}$ and $\mathrm{FL}_{2}$ are computed as

$$
\begin{aligned}
& \mathrm{FL}_{1}=\frac{\mathrm{FL}_{0} * \mathrm{HL}_{1}}{\mathrm{HL}_{0}}=\frac{100 \% * 70 \%}{71 \%}=98.6 \% \approx 99 \% \\
& \mathrm{FL}_{2}=\frac{\mathrm{FL}_{1} * \mathrm{HL}_{2}}{\mathrm{HL}_{1}}=\frac{98.6 \% * 69 \%}{70 \%}=97.2 \% \approx 97 \%
\end{aligned}
$$

Other FL values can be calculated by using the same formula and the full booking curve can be generated as following in the graph (Fig. 2).

In this graph, the solid line represents the historical booking curve and the dash line denotes the full booking curve. The booking growth ratios of each day on the full booking curve equals the ratios on the historical booking curve. It means if the target LF on NDO 0 is $100 \%$, the booking pace needs follow the pattern of the full booking curve, in order to meet the target.

The full booking curve is used as a benchmark to forecast spoilage/spill. An example is provided in Fig. 3. If the current LF on NDO 21 for one flight is at point A (62\%), which is above the full booking curve LF (58\%), based on the booking pattern, the demand will reach $100 \%$ before the departure day, so it will be a spill. If the current LF is at point $\mathrm{B}(50 \%)$, which is below the full booking curve LF (58\%), the demand will not reach $100 \%$ at the departure day, so it will be a spoilage.

By benchmarking current LF against the full booking curve on specific NDO, spoilage/spill can be forecasted. The next step is, after spoilage/spill is known, what optimal O\&D fares should be offered?

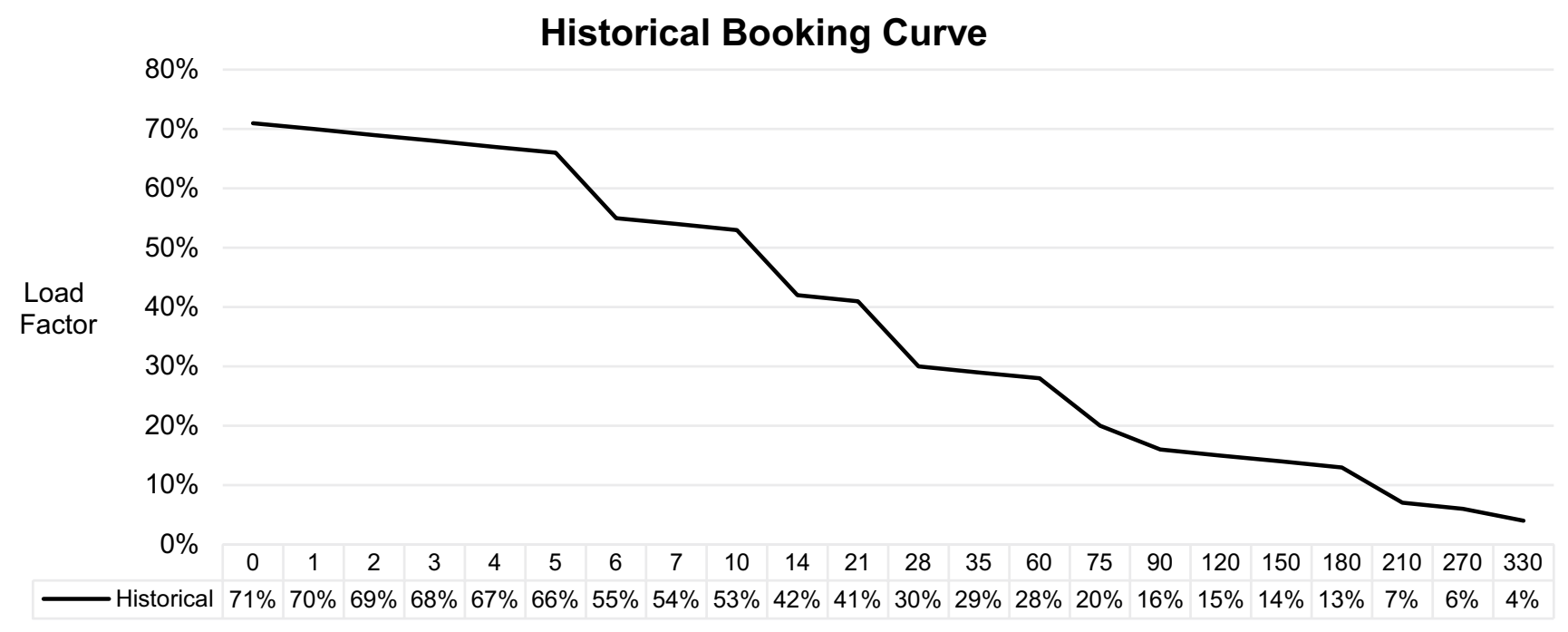

Load Factor on Each NDO

Fig. 1 An example of a booking curve 


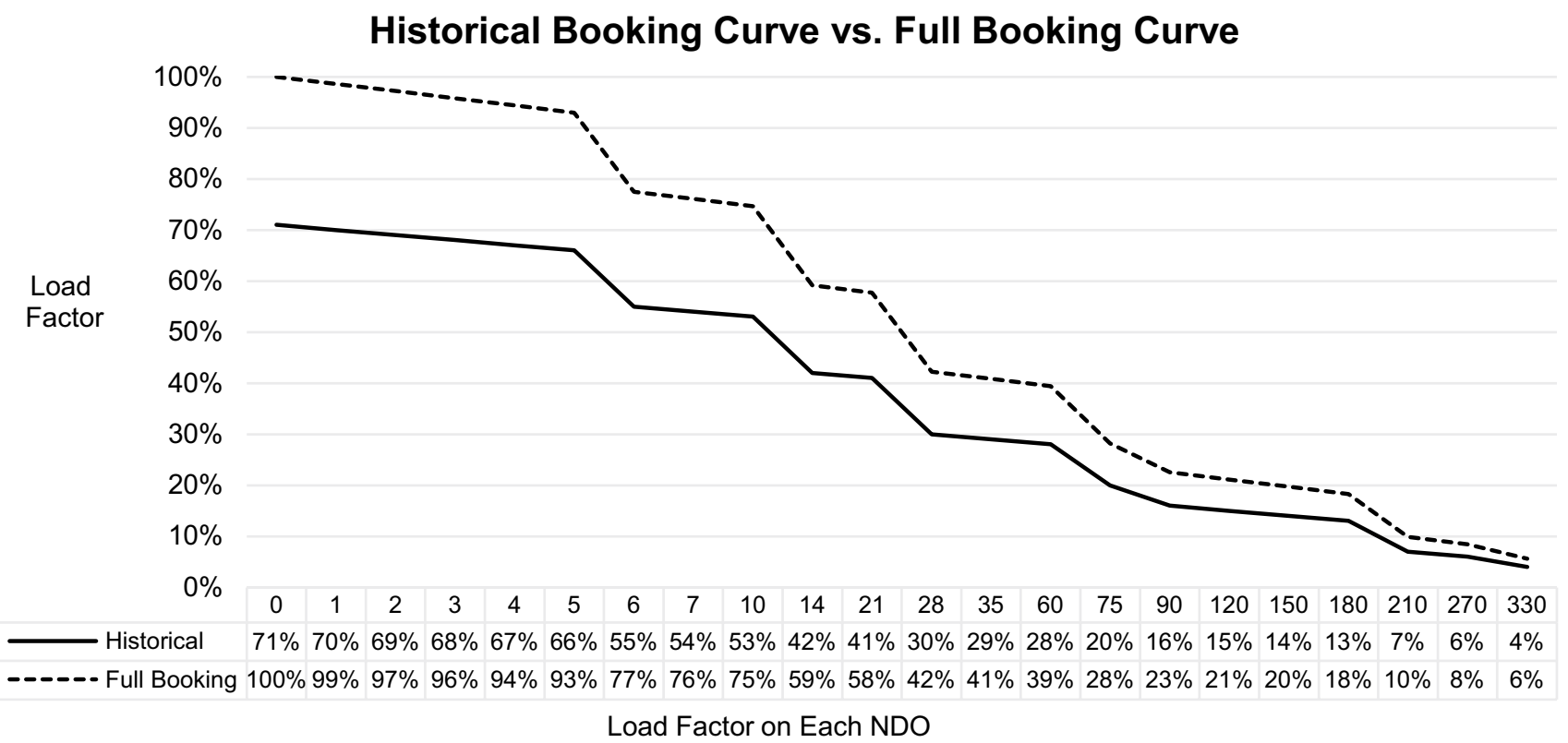

Fig. 2 Historical booking curve vs. full booking curve

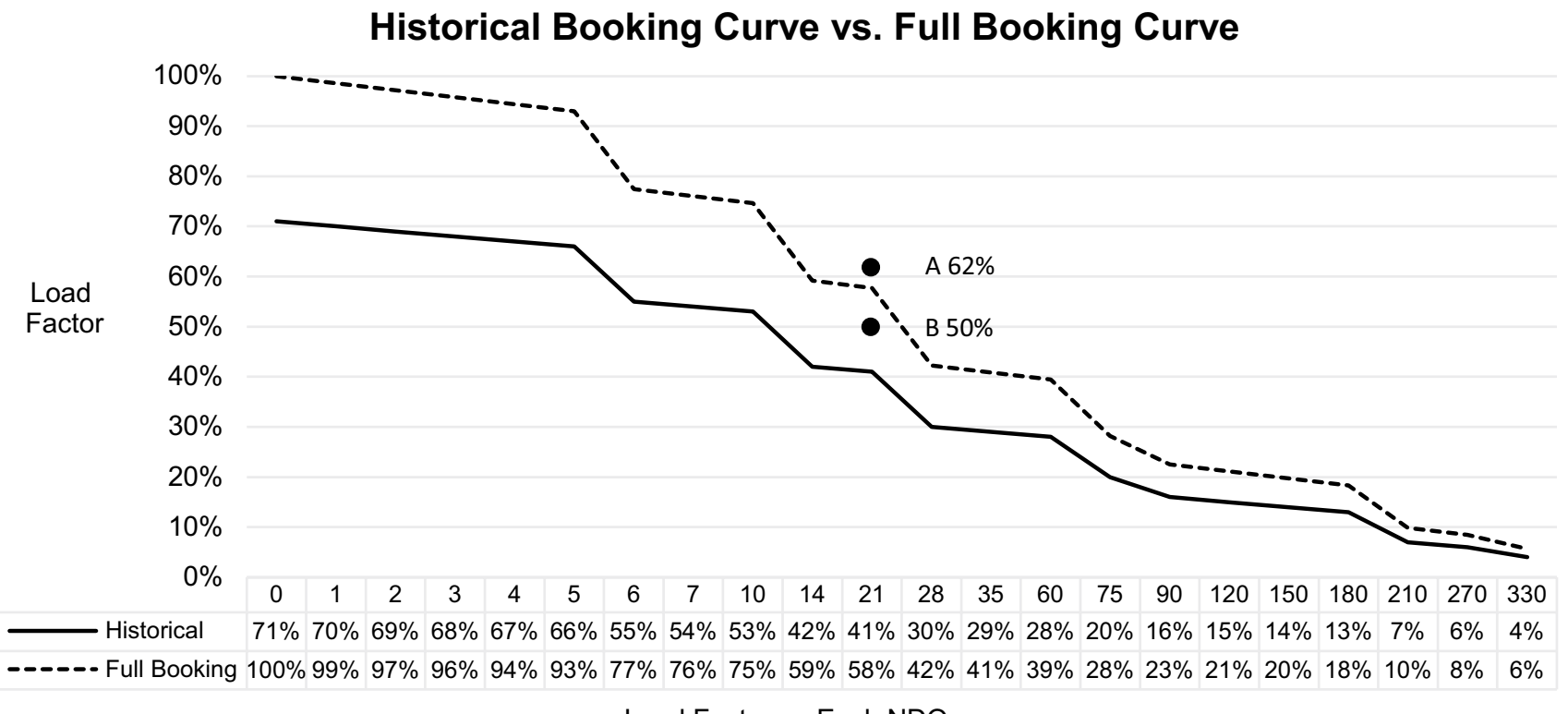

Fig. 3 Spoilage/Spill forecast by booking curves

\section{What leg fares should be offered to connecting passengers?}

Industry data shows domestic routes and leg flights recover faster than international routes and connecting flights during COVID-19 recovery. Based on this assumption, ODC model use leg flight performances as a foundation to build O\&D fare recommendations. In the airline industry, a multiplier adjustment methodology is commonly used to quote O\&D leg fares. Multipliers between 0.0 to 1.0 are multiplied by local leg fares to adjust O\&D leg fares. ODC model adopts this industry practice to provide recommendations for O\&D leg fares. The values of multipliers are generated by calculating the ratios of how much current LF is above or below the full booking curve LF. Below is the formula for spoilage situations. 
Fare $_{C 1}=$ Fare $_{L 1} *$ Multiplier

Multiplier $_{\text {Spoilage }}=\frac{\mathrm{CL}_{n}}{\mathrm{FL}_{n}}$

where in this formula, Fare ${ }_{\mathrm{Cl}}$ is the lowest available leg fare offered to connecting O\&D passengers on leg 1 and Fare ${ }_{\mathrm{L} 1}$ is the lowest available fare currently being offered to local point-to-point passengers on that leg. $\mathrm{FL}_{n}$ represents the full $\mathrm{LF}$ on NDO $\mathrm{n}$ and $\mathrm{CL}_{n}$ represents the current LF on NDO n. For instance, if the local leg fare is $\$ 100$, the current LF is $50 \%$, and the full LF is $58 \%$, the leg fare offered to O\&D passengers is $\$ 86.2$.

Fare $_{C 1}=$ Fare $_{L 1} * \frac{\mathrm{CL}_{n}}{\mathrm{FL}_{n}}=100 * \frac{50 \%}{58 \%}=86.2$

The ratio of $\mathrm{CL}_{n}$ and $\mathrm{FL}_{n}$ reflects the current demand is $86.2 \%$ of the full curve demand, so it is used as the multiplier to adjust O\&D fares, which can dynamically react to the market demand. The lower the demand is, the smaller the multiplier is and the lower the fare is, and vice versa. If one airline is more aggressive at stimulating demand during COVID19 recovery or wish to be more competitive in the market, a squared ratio or a cubed ratio could be used in the formula to generate lower O\&D fares.

If the current LF is larger than the full LF, it is in a spill situation. In spill situations, if the multiplier value is set as smaller than 1, the leg fare offered to connecting passengers will be lower than the local fare, and airlines will lose revenue by taking connecting passengers over local passengers, causing displacement costs. To prevent this, ODC model proposes to set the value of multiplier as 1 in spill situations.

Multiplier $_{\text {Spill }}=1$

Once Fare ${ }_{C}$ equals to Fare ${ }_{\mathrm{L}}$, there will be no displacement costs, as same fares are offered to connecting passenger and local passengers. Putting spoilage and spill situations together, the multiplier formula is as following:

Multiplier $=\operatorname{Min}\left(1, \frac{\mathrm{CL}_{n}}{\mathrm{FL}_{n}}\right)$

The full ODC model formulas are:

$$
\begin{aligned}
& \mathrm{FL}_{0}=100 \% \\
& \mathrm{FL}_{n}=\frac{\mathrm{FL}_{n-1} * \mathrm{HL}_{n}}{\mathrm{HL}_{n-1}},(n \geq 1) \\
& \text { Fare }_{C 1}=\operatorname{Fare}_{L 1} * \operatorname{Min}\left(1, \frac{\mathrm{CL}_{n}}{F L_{n}}\right) \\
& \text { Fare }_{C 2}=\text { Fare }_{L 2} * \operatorname{Min}\left(1, \frac{\mathrm{CL}_{n}}{\mathrm{FL}_{n}}\right) \\
& \text { Fare }_{C}=\operatorname{Max}\left[\left(\text { Fare }_{C 1}+\text { Fare }_{C 2}\right), \text { Fare }_{L 1}, \text { Fare }_{L 2}\right]
\end{aligned}
$$

where in this formula, assuming the itinerary of a connecting passenger involves two legs as leg 1 and leg 2, Fare ${ }_{\mathrm{L} 1}$ and Fare ${ }_{\mathrm{L} 2}$ are local leg fares, and Fare $\mathrm{C}_{1}$ and Fare $\mathrm{C}_{2}$ are the optimal leg fares offered to the connecting passenger on leg 1 and leg 2, respectively. Fare $\mathrm{C}_{\mathrm{C}}$ is the total fare offered to this connecting passenger, which is the sum of Fare ${ }_{\mathrm{C} 1}$ and Fare $_{\mathrm{C} 2}$. One practical restriction is considered - O\&D fare should not be lower than any individual leg fares, so Fare ${ }_{\mathrm{C}}$ value is the maximum value among Fare $_{\mathrm{L} 1}$, Fare $_{\mathrm{L} 2}$ and the sum of $\mathrm{Fare}_{\mathrm{Cl}}$ and $\mathrm{Fare}_{\mathrm{C} 2}$. It's optional for airlines to remove this restriction if airlines wish to promote more O\&D sale, especially during COVID-19 recovery.

An example of an O\&D itinerary involves two legs as leg 1 and leg 2 is shown as below (Table 2).

$\mathrm{FL}_{1}=58 \%, \mathrm{FL}_{2}=58 \%$,

Local leg 1 fare $=\$ 100$, Local leg 2 fare $=\$ 100$,

Spoilage $\mathrm{CL}_{1}=50 \%$, spoilage $\mathrm{CL}_{2}=30 \%$,

Spill $\mathrm{CL}_{1}=62 \%$, spill $\mathrm{CL}_{2}=80 \%$.

There are three different scenarios.

\section{Both leg 1 and leg 2 are in spoilage}

Current LF for leg 1 is $50 \%$ and Current LF for leg 2 is $30 \%$, so the multipliers for leg 1 and leg 2 are 0.862 and 0.517 , respectively. As leg 2 demand is lower than leg 1, the multiplier of leg 2 is smaller, which can stimulate more O\&D demand on leg 2. The optimal fare for O\&D passengers is $\$ 137.9$, as the sum of $\$ 86.2$ and $\$ 51.7$.

\section{Leg 1 is in spoilage and leg 2 is in spill}

Because leg 2 is in a spill situation with high demand, the leg 2 O\&D fare equals to the local fares as $\$ 100$, so that the airline doesn't lose any revenue for taking connecting passengers over local passengers. Meanwhile, as leg 1 demand is low, O\&D fare on leg $1(\$ 86.2)$ is low so airlines can still stimulate some connecting demands on leg 1 .

\section{Both leg 1 and leg 2 are in spill}

As the demands on the both flights are high, the leg fares for O\&D passengers are the same with local passengers. The

Table 2 An example of ODC model in 3 scenarios

\begin{tabular}{llllll}
\hline \multicolumn{2}{l}{ Leg spoilage/spill situations } & & \multicolumn{2}{l}{ Optimal fares for O\&D passengers } \\
\cline { 1 - 1 } Leg 1 & Leg 2 & & Leg 1 & Leg 2 & Total \\
\hline Spoilage & Spoilage & & $\$ 86.2$ & $\$ 51.7$ & $\$ 137.9$ \\
Spoilage & Spill & & $\$ 86.2$ & $\$ 100$ & $\$ 186.2$ \\
Spill & Spill & & $\$ 100$ & $\$ 100$ & $\$ 200$ \\
\hline
\end{tabular}


total fare equals to the sum of local leg fares as $\$ 200$. By offering the same fares, airlines eliminate connecting passengers' displacement costs in both spill flights.

To apply 0DC model, airlines need store historical data of local passengers to generate historical booking curves. Once O\&D booking requests are accepted on one flight, they need to be added to the current booking curve to dynamically reflect the current LF and flight availability. It is also optional for airlines to incorporate other KPIs, such as RASM/RASK, total revenue, or average fare, to customize booking curves based on airlines' needs.

\section{Simulation}

To examine ODC model, a simulation is conducted by running 0DC model against real airline industry data. The simulation setup and result analysis are briefly described in this section.

\section{Simulation setup}

This simulation is designed in spreadsheets by using VBA programming. It simulates the booking process by using ODC model to affect the decisions of accepting or rejecting O\&D connecting booking requests. The historical data are collected from two airlines in two countries. Two types of networks are selected:

Type 1 network

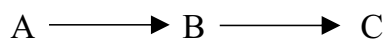

Itinerary count: 3 (A-B, B-C, A-B-C)

Network data set: $3(a, b, c)$

Type 2 network

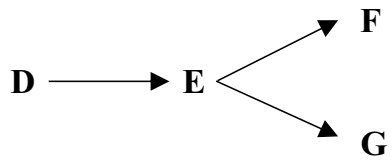

Itinerary count: 5 (D-E, E-F, E-G, D-E-F, D-E-G)

Network data set: $2(d, e)$

Three sets of historical data (a, b, c) are collected from type 1 network. Each data set has 3 itineraries (A-B, B-C, A-B-C). Two sets of data (d, e) are collected from type 2 network. Each data set has 5 itineraries (D-E, E-F, $\mathrm{E}-\mathrm{G}, \mathrm{D}-\mathrm{E}-\mathrm{F}, \mathrm{D}-\mathrm{E}-\mathrm{G})$. The total number of itineraries in this simulation is $3 * 3+5 * 2=19$. All historical data are selected by day of week (DOW). Each itinerary in one data set includes 9 to 21 samples with departure date range from 3 months to 1 year. The date range variance derives from airlines' flight schedules. Economy class data are used in the data pool, premium class data and discrete class data are excluded.

\section{Result analysis}

The ODC model simulated result is compared with the airlines' actual revenue for analysis. In the simulated environment, ODC model takes the historical local demand as the data pool to build booking curves, uses its model algorithm to offer O\&D fares and impacts the decisions of taking or rejecting connecting passengers. All results in 5 networks are displayed as below followed by explanations. As the flight data are collected from two different countries, revenues in type 1 and type 2 networks are in different currencies (Tables 3, 4, 5, 6, 7).

The sample size number indicates how many historical flights are included for each itinerary. The forecasting model used is additive pick up model. The connection ratio represents the percentage of connecting traffic in total traffic. Local LF represents the post-departure LF of local passengers and the total LF includes O\&D connecting passengers. The revenue gain percentage or loss percentage is measured by comparing the simulated revenue numbers with airlines' actual revenue numbers. The average connection gain, network gain and connection ratio for each network are presented in a graph as below (Fig. 4).

The stimulated result shows incremental total network revenue gain by running $0 \mathrm{DC}$ model in 5 networks. As type 1 networks are in a simpler network structure, the connection ratios are higher than the ratios in type 2 networks. The simulated results show an over $7 \%$ connection revenue gain and an over $3 \%$ network revenue gain for type 1 networks.

Type 2 networks are in a more complicated network structure, so the connection ratio of each long-haul itinerary is lower and booking numbers are smaller. As the base numbers are small, the connection revenue gain percentages are in large magnitudes. The average connection revenue gains for network $d$ and network e are $34.6 \%$ and $-48.6 \%$, and total network gains are $0.7 \%$ and $0.3 \%$, respectively. The negative connection revenue gain in network e is caused by the spill situation in leg D-E (local LF as 100\%). In the airline actual environment, two connecting bookings were accepted for D-E-F with low fares, so their displacement costs caused revenue leakage. In the simulated ODC model environment, same leg fare was offered to connecting passengers to eliminate displacement costs and no connecting booking requests were accepted. As a result, two more seats 
Table 3 Simulation result of type 1 network a

\begin{tabular}{|c|c|c|c|c|c|c|c|}
\hline \multirow[t]{3}{*}{ Sample size } & \multicolumn{2}{|l|}{13} & \multirow{2}{*}{\multicolumn{2}{|c|}{$\frac{\text { Connection ratio }}{\text { Booking }}$}} & \multirow{2}{*}{\multicolumn{2}{|c|}{$\frac{51.4 \%}{\text { Revenue }}$}} & \multirow[t]{3}{*}{ Revenue gain } \\
\hline & \multicolumn{2}{|l|}{$\mathrm{LF}$} & & & & & \\
\hline & Local (\%) & Total (\%) & Actual & ODC & Actual & ODC & \\
\hline $\mathrm{A}-\mathrm{B}$ & 26.9 & 91.4 & 46 & 46 & 16,400 & 16,400 & \\
\hline $\mathrm{B}-\mathrm{C}$ & 35.7 & 100.0 & 61 & 61 & 51,230 & 51,230 & \\
\hline A-B-C & & & 113 & 110 & 112,750 & 120,785 & $7.1 \%$ \\
\hline Total & & & & & 180,380 & 188,415 & $4.5 \%$ \\
\hline
\end{tabular}

Table 4 Simulation result of type 1 network b

Table 5 Simulation result of type 1 network c

Table 6 Simulation result of type 2 network $\mathrm{d}$

\begin{tabular}{|c|c|c|c|c|c|c|c|}
\hline \multirow[t]{3}{*}{ Sample size } & \multicolumn{2}{|l|}{21} & \multirow{2}{*}{\multicolumn{2}{|c|}{$\frac{\text { Connection ratio }}{\text { Booking }}$}} & \multicolumn{2}{|l|}{$32.1 \%$} & \multirow[t]{3}{*}{ Revenue gain } \\
\hline & \multicolumn{2}{|l|}{ LF } & & & \multicolumn{2}{|c|}{ Revenue } & \\
\hline & Local (\%) & Total (\%) & Actual & ODC & Actual & ODC & \\
\hline A-B & 42.0 & 75.9 & 70 & 70 & 32,730 & 32,730 & \\
\hline $\mathrm{B}-\mathrm{C}$ & 39.9 & 73.8 & 57 & 57 & 18,290 & 18,290 & \\
\hline $\mathrm{A}-\mathrm{B}-\mathrm{C}$ & & & 60 & 49 & 32,800 & 35,843 & 9.3 \\
\hline Total & & & & & 83,820 & 86,863 & 3.6 \\
\hline
\end{tabular}

\begin{tabular}{|c|c|c|c|c|c|c|c|}
\hline \multirow[t]{3}{*}{ Sample size } & \multirow{2}{*}{\multicolumn{2}{|c|}{ LF }} & \multirow{2}{*}{\multicolumn{2}{|c|}{$\frac{\text { Connection ratio }}{\text { Booking }}$}} & \multirow{2}{*}{\multicolumn{2}{|c|}{$\frac{26.7 \%}{\text { Revenue }}$}} & \multirow{3}{*}{$\begin{array}{l}\text { Revenue } \\
\text { gain (\%) }\end{array}$} \\
\hline & & & & & & & \\
\hline & Local (\%) & Total (\%) & Actual & ODC & Actual & ODC & \\
\hline A-B & 53.8 & 84.1 & 93 & 93 & 23,740 & 23,740 & \\
\hline B-C & 50.9 & 81.2 & 88 & 88 & 44,420 & 44,420 & \\
\hline $\mathrm{A}-\mathrm{B}-\mathrm{C}$ & & & 66 & 52 & 36,740 & 40,114 & 9.2 \\
\hline Total & & & & & 104,900 & 108,274 & 3.2 \\
\hline
\end{tabular}

\begin{tabular}{|c|c|c|c|c|c|c|c|}
\hline \multirow[t]{3}{*}{ Sample size } & \multicolumn{2}{|l|}{13} & \multirow{2}{*}{\multicolumn{2}{|c|}{$\frac{\text { Connection ratio }}{\text { Booking }}$}} & \multirow{2}{*}{\multicolumn{2}{|c|}{$\frac{1.6 \%}{\text { Revenue }}$}} & \multirow{3}{*}{$\begin{array}{l}\text { Revenue } \\
\text { gain (\%) }\end{array}$} \\
\hline & \multicolumn{2}{|l|}{$\mathrm{LF}$} & & & & & \\
\hline & Local (\%) & Total $(\%)$ & Actual & ODC & Actual & ODC & \\
\hline D-E & 93.9 & 99.2 & 169 & 169 & 8533 & 8533 & \\
\hline $\mathrm{E}-\mathrm{F}$ & 77.8 & 83.1 & 140 & 140 & 6340 & 6340 & \\
\hline $\mathrm{E}-\mathrm{G}$ & 66.7 & 68.2 & 119 & 119 & 11,228 & 11,228 & \\
\hline D-E-F & & & 4 & 6 & 316 & 389 & 23.1 \\
\hline D-E-G & & & 3 & 4 & 237 & 346 & 46.0 \\
\hline Total & & & & & 26,654 & 26,836 & 0.7 \\
\hline
\end{tabular}

were available for higher-yield local passengers. Although it leads to a revenue loss for the connecting revenue, it brings revenue gains for both local revenue and network revenue.

The data analysis also shows a high correlation between network revenue gain with connection ratio. ODC models provides more revenue gain when the connection ratio is higher (Table 8, Fig. 5). 
Table 7 Simulation result of type 2 network e

\begin{tabular}{|c|c|c|c|c|c|c|c|}
\hline \multirow[t]{3}{*}{ Sample size } & \multicolumn{2}{|l|}{13} & \multicolumn{2}{|c|}{ Connection ratio } & \multicolumn{2}{|l|}{$0.9 \%$} & \multirow[t]{3}{*}{ Revenue gain } \\
\hline & \multicolumn{2}{|l|}{ LF } & \multicolumn{2}{|c|}{ Booking } & \multicolumn{2}{|c|}{ Revenue } & \\
\hline & Local & Total & Actual & ODC & Actual & ODC & \\
\hline D-E & 100.0 & 101.4 & 182 & 180 & 11,166 & 11,346 & \\
\hline E-F & 63.3 & 64.7 & 114 & 114 & 5664 & 5664 & \\
\hline $\mathrm{E}-\mathrm{G}$ & 88.9 & 90.0 & 160 & 160 & 8610 & 8610 & \\
\hline D-E-F & & & 2 & 0 & 104 & 0 & -100.0 \\
\hline D-E-G & & & 2 & 2 & 104 & 107 & 2.7 \\
\hline Total & & & & & 25,648 & 25,727 & 0.3 \\
\hline
\end{tabular}

\section{Simulation Result}

$60.0 \%$

$40.0 \%$

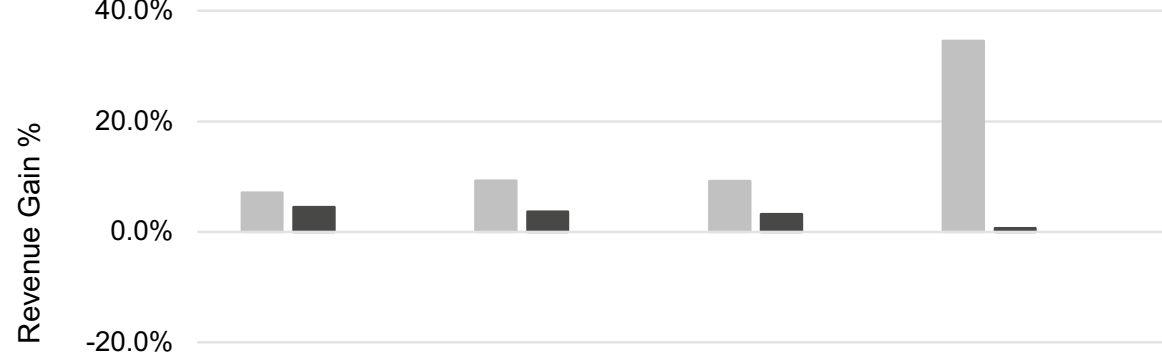

$-40.0 \%$

\begin{tabular}{|l|c|c|c|c|c|}
\hline \multicolumn{1}{|c|}{$-60.0 \%$} & Network a & Network b & Network c & Network d & Network e \\
\hline Connection Rev. Gain & $7.1 \%$ & $9.3 \%$ & $9.2 \%$ & $34.6 \%$ & $-48.6 \%$ \\
\hline - Network Rev. Gain & $4.5 \%$ & $3.6 \%$ & $3.2 \%$ & $0.7 \%$ & $0.3 \%$ \\
\hline Connection Ratio & $51.4 \%$ & $32.1 \%$ & $26.7 \%$ & $1.6 \%$ & $0.9 \%$ \\
\hline
\end{tabular}

Fig. 4 Simulation result

Table 8 Correlation analysis

\begin{tabular}{lll}
\hline & Network revenue gain & $\begin{array}{l}\text { Con- } \\
\text { nection } \\
\text { ratio }\end{array}$ \\
\hline $\begin{array}{ll}\text { Network revenue gain } \\
\text { Connection ratio }\end{array}$ & 1 & \\
\hline
\end{tabular}

\section{Conclusions}

While traditional O\&D RM models provide more revenue benefits than leg RM models, the practical and realistic challenges of O\&D models could negatively impact the revenue potential, so some new programs should be considered to effectively handle the full O\&D complexity (Tirumalachetty et al. 2017). The COVID-19 has further brought the urgency for a new O\&D model to quickly deal with market uncertainty in a more flexible method.

The novelty of this paper is to propose ODC model as a simplified O\&D RM model to solve complicated O\&D problems and achieve revenue goals. The simulation result indicates incremental network revenue gain by running ODC models against real airline data. ODC model solves the five limitations in traditional models: 
Fig. 5 Revenue gain and connection ratio in each network

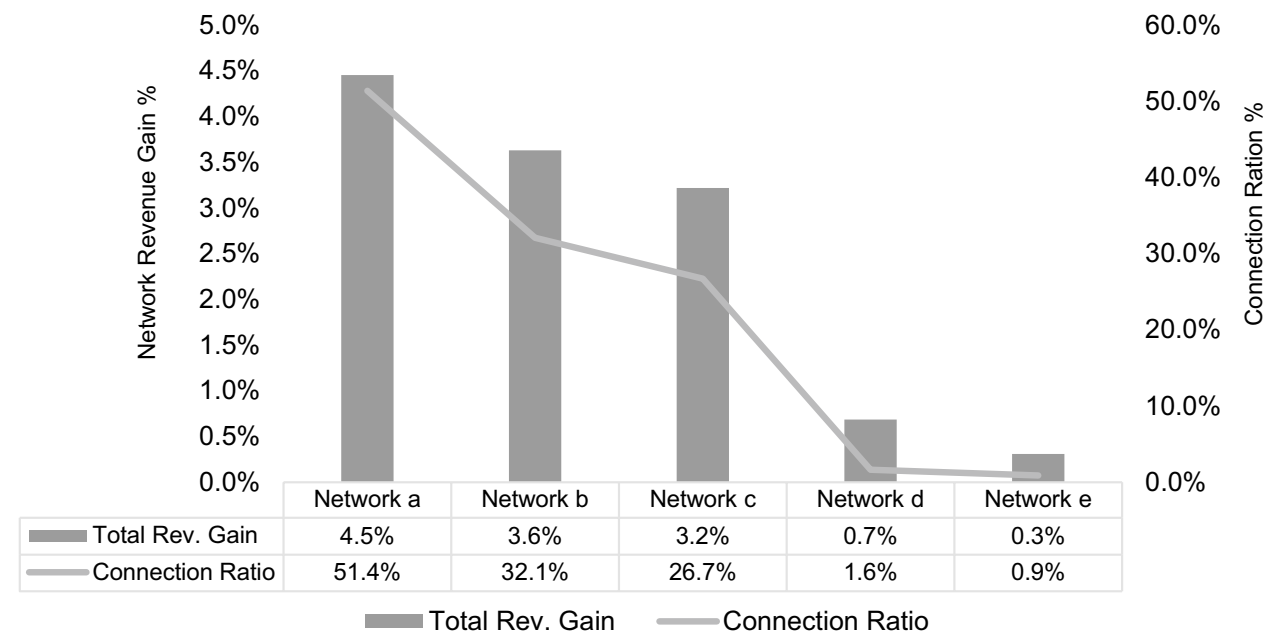

\section{From complexity to simplicity}

From a programming perspective, ODC avoids the ODF level of data collection and computation, making it very efficient in programming. From an operational perspective, ODC model adjust $O \& D$ fares based on local leg fares, so airlines just need to focus on leg optimization and the optimal O\&D fares will be adjusted accordingly in the model. This is based on the market preformation that local markets recover faster than the connecting O\&D routes during COVID-19 recovery. From users' perspective, a model can only reach its maximum potential when users fully comprehend it (Lapp and Weatherford 2014). As the algorithm in 0DC model is very simple and straightforward, it's very easy for analysts to understand and interact with the model.

\section{From theoretical to practical}

Most traditional O\&D models are based on strong foundations of academic theories. 0DC model is built from a practical heuristic. It adopts industry common practices and incorporates them into the model, such as booking curve methodology and multiplier adjustment methodology. These practices are very flexible to modify and adjust based on market fluctuations and they empower analysts to deal with unexpected crises more efficiently.

\section{Eliminate displacement costs}

Traditional O\&D models assume every connecting passenger is associated with a displacement cost. ODC model proposes to first consider different displacement scenarios in spoilage and spill situations. It points out that no displacement costs incurred in spoilage situations. In spill situations, 0DC model offers same fares to connecting passengers with local passengers to eliminate displacement costs. Therefore, no displacement costs incur when applying ODC model, so this model is named as zero displacement cost model.

\section{Forecast on flight level}

As flight booking curve reflects demand pattern on a flight level, the forecasting granularity in ODC is flight level instead of ODF level, so it solves the "small numbers" problem in most O\&D models and "zero numbers" problem during COVID-19. 0DC model uses flight level forecast to reflect demand price elasticity in a bigger picture.

\section{Quick response}

For business needs, airlines require instant optimization whenever one O\&D booking request comes in. This requires frequent model recalculations. Airlines also demand quick responses when crisis happen. This requires in-time model recalibration. The high complexity of traditional O\&D models increases the processing time. The simplicity of ODC model makes it a very efficient model to meet airlines' needs of frequent model recalculation and quick response to market uncertainty.

As for the future work, 0DC model can be further evaluated against other O\&D models and be put into simulations with more extensive networks. Researchers may consider incorporating some contextual data, such as pandemic statistics and travel policies, into model development research to help airline manage flights during the post-COVID-19 recovery. 


\section{References}

Belobaba, Peter, Amedeo Odoni, and Cynthia Barnhart (eds.). 2015. The global airline industry. Hobokn: Wiley.

Bertsimas, Dimitris, and Sanne De Boer. 2005. Simulation-based booking limits for airline revenue management. Operations Research 53 (1): 90-106.

Lapp, Marcial, and Larry Weatherford. 2014. Airline network revenue management: Considerations for implementation. Journal of Revenue and Pricing Management 13 (2): 83-112.

McGill, Jeffrey I., and Garrett J. VanRyzin. 1999. Revenue management: Research overview and prospects. Transportation science 33 (2): 233-256.

Saranathan, K., K. Peters, and M. Towns. 1999. Revenue Management at United Airlines. AGIFORS Reservations and Yield Management Study Group, April 28.

Tirumalachetty, Sumala, Vamsidhar Kodam, Goda Doreswamy, and Mukund Shankar. 2017. Unlocking the value from origin and destination revenue management. Journal of Revenue and Pricing Management 16 (6): 607-620.
Wei, Yuanyuan Yuanyuan Julie. 1997. Airline OD control using network displacement concepts. PhD diss., Massachusetts Institute of Technology.

Williamson, Elizabeth Louise. 1992. Airline network seat inventory control: Methodologies and revenue impacts. PhD diss., Massachusetts Institute of Technology.

Publisher's Note Springer Nature remains neutral with regard to jurisdictional claims in published maps and institutional affiliations.

Landie Qiu is a Senior Manager at Accelya and specialized in Revenue Management. She has implemented RM systems in six airlines. Landie holds a M.S. in Hospitality Management from Pennsylvania State University. Her thesis was published on Journal of Revenue and Pricing Management as a research article. She is a member of AGIFORS (The Airline Group of the International Federation of Operational Research Societies). Landie has been invited as a guest speaker to many industry conferences and universities around the world. 